\title{
DARPA's small satellite programme shrinks
}

Washington. Recent cuts in spending for small US satellite technology leave this stilldeveloping field without one of its main sources of funding, highlighting the precarious foothold that 'smallsats' have in the overall US space programme.

Congress, in its 1993 defence appropriations bill, deleted $\$ 30.4$ million for three programmes requested by the Defense Advanced Research Projects Agency (DARPA). Two would have led to tests in space of new, miniaturized communications and remote sensing technologies, while the third would have produced a common satellite 'bus' to provide cheaper and quicker flight opportunities for small orbiting payloads.

Congress agreed to spend $\$ 18$ million for other DARPA space activities, however, including the first flight next spring of the Taurus mobile launch system for small payloads.

More than any other government agency, DARPA has acted as an incubator for the fledgling small satellite and small launch industries. It has financed development of two new small launchers - the Pegasus aeroplane-launched rocket and the new Taurus vehicle - both built by the Orbital Sciences Corporation (OSC) in Fairfax,
Virginia. Other DARPA research has been directed at reducing the size, weight and cost of components to be used in future military satellites.

Small satellites, say advocates, hold out the hope of cheaper and more frequent flights that would accommodate more people. They would give scientists better access to Earth orbit for experiments in astronomy, space physics, materials science and related fields.

Critics of the three programmes - the Advanced Satellite Technology and EHF Communications (ASTEC), the Collaboration on Advanced Multispectral Earth Observation (CAMEO) and the Advanced Technology Standard Satellite Bus (ATSSB) say they serve no military needs that aren't already being met by existing progamming. And with Congress eager to trim defence spending, the estimated $\$ 147$ million lifetime cost of the three projects was too tempting a target to ignore.

John Pike, a space programme analyst with the Federation of American Scientists, says that the dilemma for DARPA's space technology programme is that "either this stuff has direct mission applications, in which case it is competing with existing programmes with powerful constituencies, or it

\section{Darwin material sells briskly at Sotheby's}

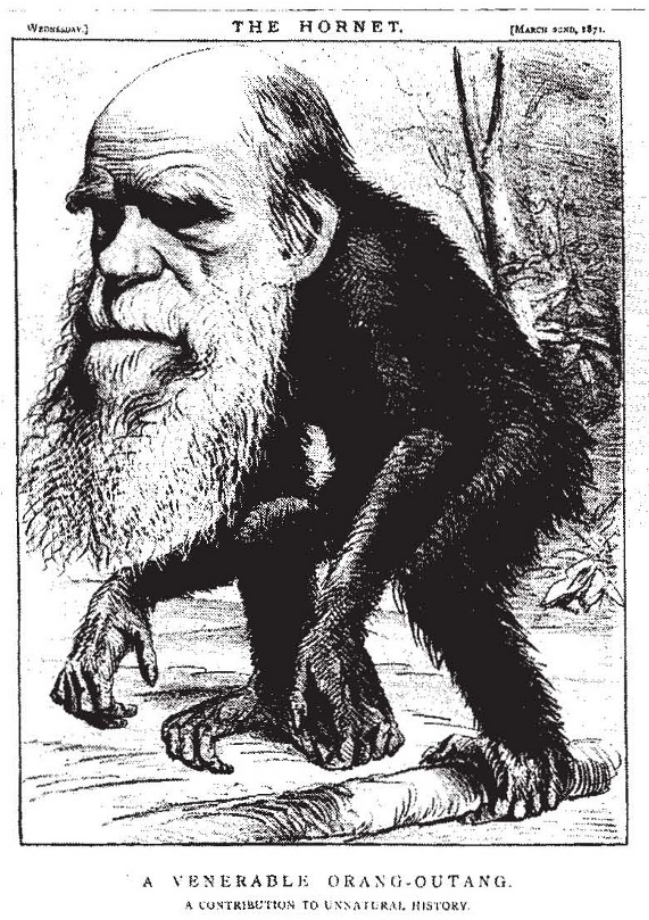

Evolution went under the hammer in London last week, when Sotheby's, the auctioneers, sold a collection of more than 400 books, pamphlets and manuscripts relating to Charles Darwin and his colleagues. The collection had been built up over the past 25 years by a Californian scientific book collector, Jeremy Norman. A single manuscript page referring to Creation and natural selection from Charles Darwin's On the Origin of Species was sold for $£ 9,350$ - more than twice the pre-auction estimate and a page from The Descent of Man went for $£ 4,400$; a first edition of the latter, estimated at between $£ 2,000$ and $£ 2,500$, fetched $£ 4,400$. included in the auction was set of anti-Darwinian pamphlets (at right), published in the 1870 s, which sold for $£ 235$.

David Dickson does not have direct mission applications, in which case it's an awfully expensive way to advance generic technology".

But Jill Stern of the International Small Satellite Organization, which supports the development of smallsats, thinks that DARPA should be engaged in pure research. "The point is to develop technology", she says.

Nongovernment researchers for the most part have ignored Pegasus flights, which cost between $\$ 11$ million and $\$ 15$ million. With few exceptions, the money to buy OSC's small rockets has come from federal agencies such as DARPA, the Strategic Defense Initiative (SDI) and the National Aeronautics and Space Administration (NASA). The dearth of outside customers for such flights raises the question of how much longer the government should operate such incubators if there is no commercial interest in them.

DARPA's role in developing smallsat technology may depend on how Presidentelect Bill Clinton redefines the mission of the 34-year-old military research agency. During the presidential campaign, Clinton suggested a civilian equivalent of DARPA for commercial technology development. Others have proposed similar concepts, ranging from a quasi-governmental Civilian Technology Corporation to a restructured DARPA for both military and civilian high technology.

A recent analysis by the Rand Corporation criticizes both ideas, however, by arguing that any federal agency is ill-equipped to deal with the constant changes in commercial technology. In addition, even a new structure would eventually lose its flexibility and develop the same institutional biases that plague existing agencies.

With DARPA's fate hanging in the balance, supporters of small satellites hope that the three programmes will be revived in the agency's budget for fiscal year 1994 beginning on 1 October 1993. If not, they must place their hopes for funding with the SDI programme, which faces its own problems in a Clinton administration, or with NASA, which has shown a growing interest in small satellites.

Tony Reichhardt

\section{Corrections}

The European Societies of Pharmacology were wrongly referred to as the European Federation of Pharmacology Societies in a recent News article about homoeopathic products (Nature 359, 469 1992).

- The picture of the Moon that appeared in last week's News section (Nature 360, 501; 1992) was taken by the Galileo spacecraft not during this month's trip around the Earth but during its initial flyby two years ago. 